\title{
Measurement of autoantibodies against human eye muscle plasma membranes in Graves' ophthalmopathy
}

\author{
MARTA FARYNA， JANUSZ NAUMAN， ANDRZEJ GARDAS
}

\begin{abstract}
Antibodies that reacted with plasma membranes of human eye muscle but showed no binding to plasma membranes of human skeletal muscle were identified in serum of patients with Graves' ophthalmopathy. Rabbit antithyroglobulin serum at a dilution of $1 \times 10^{-3}$ to $20 \times 10^{-3}$ had no effect on the binding of these antibodies to eye muscle membrane antigens. There was no correlation between antihuman eye muscle plasma membrane antibodies and antihuman thyroid membrane antibodies or antibodies against thyroglobulin.

It is suggested that specific antibodies against eye muscle membranes are present in Graves' ophthalmopathy and that this disease might represent a distinct autoimmune disorder.
\end{abstract}

\section{Introduction}

The aetiology of Graves' ophthalmopathy is not fully understood, but substantial evidence indicates that it is a separate organ specific autoimmune disorder. Though cell mediated immunity seems to be well documented, ${ }^{12}$ the presence of specific autoantibodies directed against retro-orbital antigens has only recently been reported. Kodama et al showed serum autoantibodies reacting with soluble antigens isolated from human eye muscle cytosol. ${ }^{3}$ Kendall-Taylor et al also showed autoantibodies in the serum of patients with severe infiltrating ophthalmopathy that specifically react with antigens localised in porcine eye muscle membranes. ${ }^{4}$ In the present study we measured antihuman eye muscle plasma membrane antibodies in the serum of patients with Graves' ophthalmopathy, using the ability of protein A from Staphylococcus aureus to interact with the Fc fragment of IgG. We also attempted to study the possible correlation between these autoantibodies and antihuman thyroid membrane antibodies and antithyroglobulin antibodies.

\section{Patients and methods}

\section{PATIENTS}

We studied 20 patients (seven men, 13 women) aged 22-70 with infiltrating Graves' ophthalmopathy. The severity of the eye signs ranged from class 2 to class 6 in the classification of the American Thyroid Association. ${ }^{5}{ }^{6}$ At the time of the study five patients were hyperthyroid, nine were euthyroid but had been hyperthyroid in the

\footnotetext{
Department of Biochemistry, Medical Centre of Postgraduate Education, 01-813 Warsaw, Poland

MARTA FARYNA, MD, senior assistant

JANUSZ NAUMAN, MD, PHD, professor of medicine

ANDRZEJ GARDAS, MSC, PHD, associate professor of biochemistry

Correspondence to: Professor J Nauman.
}

past, and six had no signs of thyroid disease. Nineteen healthy blood donors served as controls.

ESTIMATION OF ANTIEYE MUSCLE PLASMA MEMBRANE ANTIBODIES

Protein A (Pharmacia Fine Chemicals, Sweden) was labelled with iodine- 125 by means of iodogen (1, 3, 4, 6-tetrachloro, $3 \alpha, 6 \alpha$ diphenylglycouril; Pierce Co, USA) and purified as described by Gardas et al. ${ }^{7}$

Crude human eye muscle or skeletal muscle plasma membranes were prepared by the method of Amir et al. ${ }^{8}$ Both eye muscles and skeletal muscles were obtained at necropsy from subjects without a history of autoimmune disease within 24 hours of death. Antieye muscle membrane antibodies were estimated by a slight modification of the method of Gardas et al. $^{7}$ The crude fraction of human eye muscle membrane $(0.5 \mathrm{mg}$ protein) diluted in $250 \mu 110 \mathrm{mM}$ phosphate buffer, $\mathrm{pH} 7 \cdot 4$, containing $50 \mathrm{mM}$ sodium chloride and ovine albumin $(1 \mathrm{~g} / \mathrm{l})$ was first preincubated with $50 \mu \mathrm{l}$ serum for two hours at $37^{\circ} \mathrm{C}$ and then left overnight at $4^{\circ} \mathrm{C}$. After preincubation $1 \mathrm{ml}$ phosphate buffer was added and the tubes mixed and centrifuged at $10000 \mathrm{~g}$ for 10 minutes at $4^{\circ} \mathrm{C}$. The supernatant was discarded and the pellet washed with $1 \mathrm{ml}$ cold buffer. Eye muscle plasma membranes preincubated with serum (100 $\mu \mathrm{g}$ protein) were then incubated with ${ }^{125} \mathrm{I}$ protein $\mathrm{A}(50000 \mathrm{cpm})$ for two hours at $4^{\circ} \mathrm{C}$. The reaction was stopped by adding $1 \mathrm{ml}$ cold phosphate buffer, and samples were centrifuged at $10000 \mathrm{~g}$ for 10 minutes at $4^{\circ} \mathrm{C}$. The supernatant was discarded and the radioactivity in the resulting pellet counted in a 80000 Wallac-LKB counter.

The final results were expressed as an antieye muscle membrane antibody index. The index was calculated by dividing the percentage binding of ${ }^{125} \mathrm{I}$ protein $\mathrm{A}$ to plasma membranes preincubated with test serum minus non-specific binding by the percentage binding of ${ }^{125}$ I protein A to plasma membranes preincubated with normal serum minus non-specific binding. Non-specific binding was the binding of ${ }^{125}$ I protein $\mathrm{A}$ to membranes preincubated with buffer only.

\section{OTHER PROCEDURES}

Antithyroid plasma membrane antibodies were estimated by the method of Gardas et al. ${ }^{7}$ Further studies have shown that an antithyroid plasma membrane antibody index above 1.6 should be considered to be positive for the presence of antithyroid plasma membrane antibodies. ${ }^{9}$

Antithyroglobulin antibodies were estimated by radioimmunoassay as described by Kielczynski. ${ }^{10}$ Antithyroglobulin antibodies with a titre of $1 / 4 \times 10^{6}$ were obtained by immunisation of rabbits with highly purified human thyroglobulin. ${ }^{10}$ The Cochran-Cox test was used to evaluate the significance of the results.

\section{Results}

Values of the antihuman eye muscle plasma membrane antibody index in patients with Graves' ophthalmopathy varied from 0.81 to 2.17 and in controls from 0.53 to 1.55 (fig 1). The upper limit of normal for the index was therefore chosen as 1.55 . The mean index in patients and controls was significantly different (1.66 (SE 0.33) v $1.00(0 \cdot 29), \mathrm{p}<0 \cdot 001)$

When human skeletal muscle plasma membranes were used as a source of antigen no significant difference in antihuman eye muscle plasma membrane antibody index was found between the patients with Graves' ophthalmopathy and the controls $(1.04(0.22) v 1.00$ $(0 \cdot 11))$.

To exclude a possible role of thyroglobulin in the binding of antihuman eye muscle plasma membrane antibodies to putative antigens, preincubation mixtures of pooled serum from patients and from 
controls were enriched with rabbit antithyroglobulin antibodies at dilutions from $1 \times 10^{-3}$ to $20 \times 10^{-3}$. At these dilutions the thyroglobulin antibodies had no effect on ${ }^{125}$ I protein A binding to membranes preincubated with serum from either the patients or the controls (fig 2).

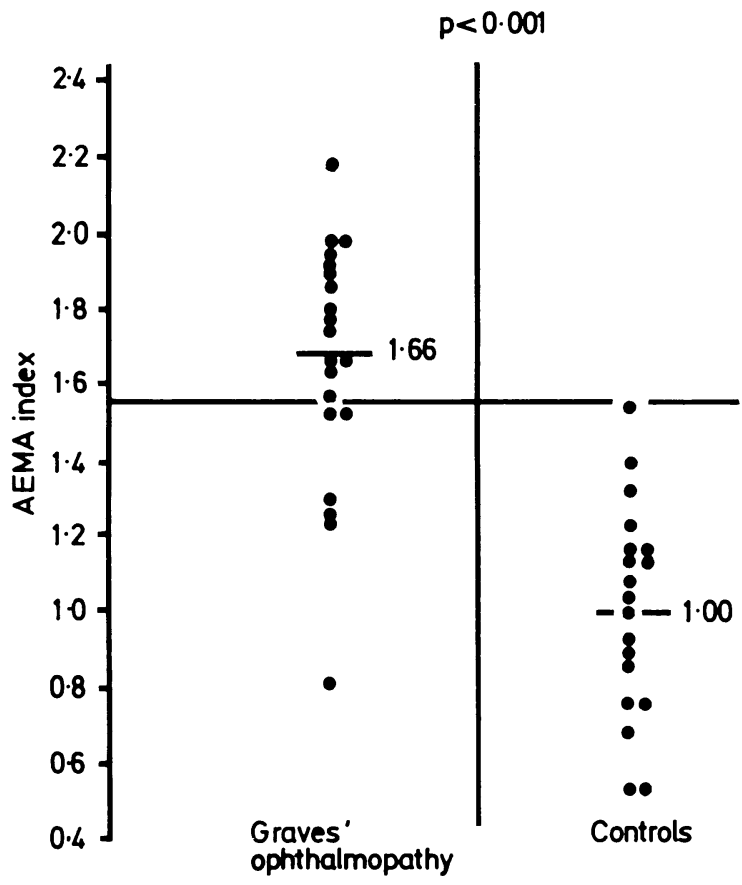

FIG 1-Antihuman eye muscle plasma membrane antibody (AEMA) index in patients with Graves' ophthalmopathy and controls.

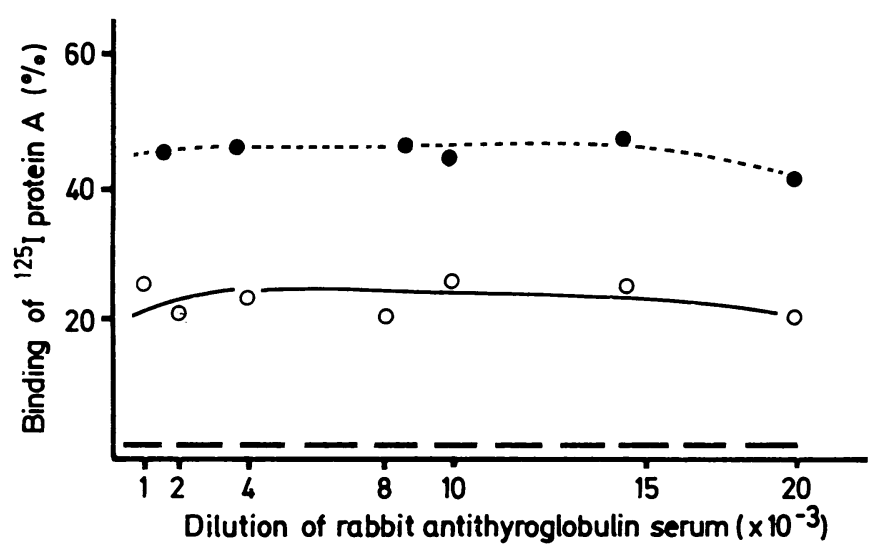

FIG 2-Influence of antithyroglobulin antibodies on ${ }^{125} \mathrm{I}$ protein $\mathrm{A}$ binding to eye muscle plasma membranes preincubated with pooled serum from patients with Graves' ophthalmopathy ( - ...healthy blood donors $(\mathrm{O}-\mathrm{O})$, or buffer alone $(--)$.

To investigate whether antibodies against eye muscle plasma membranes and thyroid plasma membranes represent the same type of IgG the antihuman eye muscle plasma membrane antibody and antihuman thyroid membrane antibody indexes obtained in the same patients were compared, but no correlation could be demonstrated $(r=-0 \cdot 07)$. Similarly, there was no correlation between the antihuman eye muscle plasma membrane antibody index and titres of thyroglobulin antibodies in the same patients $(r=0 \cdot 22)$.

\section{Discussion}

Using the ability of protein A to interact with Fc fragment of IgG we were able to show the presence of antibodies that react with human eye muscle plasma membranes in most patients with Graves' ophthalmopathy. We also showed that these antibodies are specific as they did not react with human skeletal muscle plasma membranes. The presence of such $\underset{T}{T}$ antibodies was recently reported by Kendall-Taylor et al, who $\frac{3}{\infty}$ also emphasised their high specificity. ${ }^{4}$ We detected these $\varrho$ antibodies in $14(70 \%)$ of patients with Graves' ophthalmopathy. Similar results were obtained by Kodama et al, who used $\cong$ soluble human eye muscle antigens to investigate specific antibodies and obtained positive results in $75 \%$ of patients $\mathbb{D}$ studied. ${ }^{3}$ Two possibilities might explain the "negative" values o of the antihuman eye muscle plasma membrane antibody index $气$ in some of our patients. As some of the patients had a long history of eye disease they may possibly have achieved an $\stackrel{D}{\rightarrow}$ immunological remission. Alternatively, a negative index might $\bar{O}$ be due to the relatively low sensitivity of the assay as a result of $\underline{\underline{D}}$ using tissues obtained at necropsy.

In previous studies Konishi et al reported an affinity of eye $\stackrel{\mathbb{Q}}{\varrho}$ muscle for thyroglobulin. ${ }^{11}$ Mullin et al also suggested that के putative antigens present in retro-orbital tissues contain either thyroglobulin or material like thyroglobulin. ${ }^{12}$ Using specific antibodies against human thyroglobulin in a wide range of $\overrightarrow{\vec{\omega}}$ concentrations we were unable to alter the binding of IgG from o patients or controls to human eye muscle plasma membranes. These results exclude the presence of thyroglobulin in human eye muscle membranes as well as the possibility that thyro- $\mathscr{\mathscr { C }}$ globulin, within the eye muscle membrane, could be a component os of the antigen or antigens that react with autoantibodies present $\vec{D}$ in the serum of patients with Graves' ophthalmopathy.

The studies of Kodama et al and Kendall-Taylor et al $\vec{\theta}$ strongly suggest that Graves' ophthalmopathy is a separate 0 organ specific autoimmune disorder that for reasons yet un- $工$ known commonly occurs in association with hyperthyroidism. ${ }^{3}{ }^{4} \overrightarrow{0}$ In our previous studies we have shown that antithyroid plasma membrane antibodies are present in almost all patients with $\vec{c}$ Graves' disease. ${ }^{13}$ The lack of correlation between indexes of antihuman eye muscle plasma membrane antibodies and antihuman thyroid membrane antibodies in individual patients with Graves' ophthalmopathy also provides support for the $\mathrm{G}$ possibility that ophthalmopathy is an independent autoimmune disorder. Further studies are necessary to investigate the possible correlations of the level of orbital antibodies with the duration of the eye disease and with the severity of the disease.

We thank Dr J Kupryjanczyk, from the department of pathology, for collecting human eye muscles, and Professor R Hall, of Cardiff, for his advice in the preparation of this manuscript.

\section{References}

Manhieu R, Winand R. Demonstration of delayed hypersensitivity to retrobulbar and thyroid tissues in human exophthalmos. $\mathcal{F}$ Clin Endocrinol Metab 1972;34: $1090-2$

2 Munro RE, Lamki L, Row VV, Volpe R. Cell mediated immunity in the exophthalmos of Graves' disease as demonstrated by the migration inhibition $\Omega$ factor (MIF) test. F Clin Endocrinol Metab 1973;37:286-92.

3 Kodama K, Sikorska H, Bandy-Dafoe P, Bayly R, Wall JR. Demonstration of a circulating autoantibody against a soluble eye-muscle antigen in Graves' $\mathrm{O}$ ophthalmopathy. Lancet 1982 ;ii:1353-6.

4 Kendall-Taylor P, Atkinson S, Holcombe $M$. A specific IgG in Graves' ophthalmopathy and its relation to retro-orbital and thyroid autoimmunity. O Br Med F 1984;288:1183-6.

Werner SC. Classification of the eye changes in Graves' disease. 7 Clin Endocrinol D Werner SC Modification of the classification of the eye changes of Graves' disease: recommendations of the ad hoc committee of the American Thyroid Association. F Clin Endocrinol Metab 1977;44:203-4.

7 Gardas A, Czarnocka B, Nauman J. New simple and sensitive method of $N$ estimation of anti-thyroid-plasma-membrane antibodies in serum of patients $\mathrm{C}$ with autoimmune thyroid diseases. Endokrynol Pol 1982;33:295-301.

8 Amir SM, Carraway TF, Kohn LD, Winand RJ. The binding of thyrotropin to isolated bovine thyroid plasma membranes. F Biol Chem 1973;248:4092-100.

Gardas A, Czarnocka B, Faryna $M$, et al. Simple and sensitive method for $\frac{C}{\mathscr{D}}$ estimation of antithyroid plasma membrane antibodies in the serum of patients Endocrinol (Copenh) 1984;105:492-9.

10 Kielczynski K. Radioimmunological determination of thyroglobulin and anti- $T$ bodies against thyroglobulin in serum. Endokrynol Pol 1982;33:246-55.

11 Konishi J, Herman MM, Kriss JP. Binding of thyroglobulin and thyroglobulinantithyroglobulin immune complex to extra-ocular muscle membrane. (D

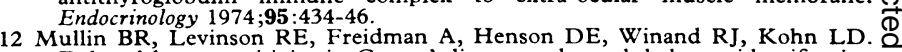
Delayed hypersensitivity in Graves' disease and exophthalmos: identification $\sigma$ of thyroglobulin in normal human orbital muscle. Endocrinology 1977;100:

13 Gardas A, Czarnocka B, Nauman J. The presence of autoantibodies directed to $O$ thyroid plasma membrane antigens in sera of patients with thyroid disorders, 1984;105:500-4.

(Accepted 26 September 1984) 